\title{
Research on the CBI System of Four-dimensional Model
}

\author{
Cuiping Ji \\ School of Foreign Studies, Wenzhou University, Wenzhou, China \\ cuiping_ji@yeah.net
}

Keywords: CBI theory; Data mining; Four-dimensional model

\begin{abstract}
This essay fist analyzes the teaching situation and existing problems of American Society and Culture, and then expounds the CBI teaching theory to be used for instruction. Based on this theory series of reformation has been carrying through in order to realize the four-dimensional teaching objects.
\end{abstract}

\section{Current situation and existing problems of teaching}

To meet the higher requirement of society and the needs of students at different levels, Wenzhou University formally introduced "College English Reform Scheme for Undergraduates in Wenzhou University" (Administration[2009]215) in 2009. One of the specific measures on curriculum in the scheme is to set a series of development courses for students who have already passed CET4 and CET6 in the second semester of sophomore year. One of these courses is American Society and Culture, aiming at systematic introduction of society and culture of America, one of the main carriers of the English language, so as to widen students' knowledge, and further improve their ability of using English in a better culture and communication environment. At present, 4 classes are having this course, consisted of students who voluntarily chose the course. The first round of teaching practice is ongoing.

The course of American Society and Culture opened before was mainly for English major, so was the corresponding reform. According to the inspection, the course of American Society and Culture are rarely covered in development course for non-English major students at a higher level in other colleges at present. Even there is, it is still in the pilot or initial phase, such as Nanjing Forestry University and China University of Mining and Technology. From the primary idea of the teaching situation of this course in other colleges, specially a series tests and surveys of the 4 classes in our university, combining with practice, current major problems of the teaching for this course are concluded as follow: (1) students have little knowledge about American society and culture. In the tests of American society and culture, students usually get low scores, with $60 \%$ of students failed. This result shows that students have a weak foundation of knowledge for the language learning. (2) students' application ability and language learning model still need improvement to promote their knowledge gaining. By learning from students' expectations for the course, teachers and themselves, over $80 \%$ of students expect to get all-round knowledge of American society and culture from classroom learning with teachers' instruction. Only a few students expect to have a chance for speaking in class; while most students are used to playing the role of a listener, lacking the consciousness and ability of solving problems with English. Therefore, to really achieve the goal of the course, a scientific teaching theory for instruction to practice, changes of the traditional result-oriented teaching, indoctrination and single model for language teaching are essential.

\section{Conception of Teaching}

To instruct the teaching of development course of American Society and Culture under the conception of teaching relied on CBI( shortened form for Content - Based Instruction), the problems above can be well solved. The theory of CBI abandons the idea of the traditional teaching method, which artificially isolates foreign language teaching. It calls for a foreign language teaching method 
integrated language and content, which transfers the teaching focus from language learning onto learning a language through knowledge enriching, so as to achieve the targets of integrating of content and language learning, as well as making improvement together.

CBI teaching theory has drawn more and more attention in foreign language teaching around the world. Since 1985, many colleges in the U.S. and Canada have launched various kinds of CBI pilot, and remarkable results have been achieved. This new teaching method has been spread rapidly within a relatively short period of time. In many countries, such as Austria, Finland, Germany, and the Netherlands etc. have adopted CBI teaching model. There among, English teaching for professional purpose, special purpose and vocational training are typical teaching environments. During 1980s, with the import of various teaching method into our country, CBI teaching conception come into view of our foreign language educators. In our country, many essays related to CBI were published in progression, introducing the definition, theoretical principle, characteristics, and mode of CBI in details. Meanwhile, quite a few scholars has started to consciously combine CBI with China English teaching practice, such as Gong Shixian (1994) "Concentration on Extensive Reading Course for English Major”, and Cao Xianwen (2005) "Concentration on English for Professional Purpose in Agriculture universities and Colleges”. In recent years, CBI teaching theory has started to be applied to college English teaching research. Professor Liu Runqing (1999) foretold that the English teaching would transfer from language skill teaching to content teaching in the future. Wei Zhefeng(2003) discussed the application of CBI teaching mode in New Horizon College English.

Generally speaking, however, the situation of existing research is foreign theory introducing oriented, with lack of practice. Research is lack of empirical statistic support, and the research on content-based college English teaching is even more inadequate, let alone the research on college development course instructed by this theory.

In conclusion, to instruct the research on development course teaching for American Society and Culture with CBI theory, can not only solve the existing problems, but also achieve the course targets practically and theoretically.

\section{Specific Content of Curriculum Reform}

Teaching content: To build a complete teaching content, integrating text, images, audios, and videos, which is three-dimensional and multiple with equal emphasis on both knowledge and content.

Teaching content is divided into 18 units, covering American geography, history, politics, laws, education and the like. Each unit has a clear theme, composed by several related topics. Take "politics" as an example, this theme can be divided into three topics of "Separation of Powers", "Bipartisan System" and "Presidential Election". Each topic has multidimensional teaching content with equal emphasis on both knowledge and language to help students improve their language skill in knowledge context.

At the same time, taking students' English level and relevant knowledge base, as well as their learning purpose and practical application in the future into consideration, it is necessary to make the text easier appropriately and try to avoid obscure theoretical knowledge, so that interesting content combining knowledge and language scientifically can be provided to students, with a major emphasis on the pragmatic teaching content.

Teaching method: The traditional education was exam-oriented for imparting knowledge with a single teaching mode shall be changed. Language skill shall be integrated into the content, interdependently, and the two shall be improved simultaneously. In the meantime, students' over passive learning mode shall be changed, too. Students' autonomy and creativity shall be given full play.

All of the teaching activities and methods should serve the four teaching targets: (1) train students' communicative competence; (2) improve students' language skill; (3) help students to understand the relevant knowledge and cultural background; (4) improve students' learning strategy.

There are three steps for classroom teaching: leading in, main activity and post-task activity. In the part of leading in, heuristic is used to guide students into the subject, with questions set at the same 
time. During the main activities, according to the flexibility of CBI, students are motivated by question-driving, output -driving and other means. Through the integration of tasks, discussion, group activities, classroom display, multimedia and teaching content, students use English to solve practical problems in specific communicative environment and cultural context, so as to improve students' communicative competence as well as their English language skills. In the post-task activities, students make presentations in groups, then assessment should be made, and finally, summarize the knowledge and language skills they've learnt. During the post-task activities, homework assignment and survey tasks can be used to foster students' autonomy and creativity.

Extracurricular activity: Organize various extracurricular activities, including knowledge contest on American society and culture, hot spot debate on American society and culture, and multimedia courseware contest, to enrich students' knowledge and train their language skills. These activities provide students with good learning atmosphere and a platform to display their skills and potential, giving a push for their comprehensive quality improvement.

Course assessment: Combine formative assessment and summative assessment; enrich the content and methods of formative assessment; enhance students' assessment for teachers and the course.

First of all, the content and methods of formative assessment should be enriched. According to the teaching targets, assessments for classroom tasks, performance, extracurricular activities, stage tests, surveys can provide a feedback for teaching process, promoting students' comprehensive development. Secondly, summative assessment should be improved to be more scientific and efficient. Course assessment is made up of 5 parts: attendance $10 \%$, network $10 \%$, classroom presentation20\%, mid-term research essay20\% and final test40\%. From multiple angles, it assesses students' study and comprehensive skills in an all-round way, which can motivate student's autonomy for learning. Finally, students' assessment for teachers should be enhanced to promote a jointly improvement for both students and teachers. Teachers are required to analysis students' feedback for teachers and the course, in order to adjust and improve teaching.

\section{Four-dimensional teaching objective for the course}

Four-dimensional teaching objective means four targets of language, content (or culture), communication (or experience) and learning strategy for college English teaching to meet. Traditional college English teaching has a single target-language skills, namely listening, speaking, reading, writing and translating. College English teaching with CBI brings content (or culture), communication (or experience) and learning strategy into teaching objective. Besides language teaching syllabus for each course, syllabus for content (or culture), communication (or experience) and learning strategy is also required. Take an example of a unit as follow:

Language teaching objective: master vocabulary, grammar and useful sentences related to the unit subject; achieve a certain level of listening, speaking, reading, writing and translating. Take "American Sports" in "American Society and Culture" as an example, its language teaching objectives includes the master of words and phrases related to four popular group sports in America, such as American Football, MLB, Touchdown, to name but a few.

Content (or culture) objective: understand relevant content and culture background. In the unit of “American Education”, students are required to understand the American educational system and relevant cultural background knowledge. For instance, what exams should American students take before entry into colleges? What qualities should they have? What are the Ivy League schools? And so forth.

Communication (or experience): students are trained to solve problems with language in specific activities or context to develop their communicative competence. In the unit of "American Food Culture”, students are divided into groups, demonstrating the differences between Chinese and American food culture. Students need to cooperate in actual scene, to finish the task. In this way, students' communicative competence is developed; meanwhile, through the demonstration of western table manners, students experience the American table manners. 
Learning strategy: it is mainly about how to study efficiently with the strategies of cognition, metacognition, emotion, communication, resource (e.g. stereoscopic teaching materials for college English) and other strategies. In the unit of “American marriage and family”, through watching the video of American wedding, comparing the difference between Chinese and American wedding, students' abilities of making comparison and analyzing can be improved; with the help of after-class feedback, students can recollect the knowledge they've gained, so as to improve their logical thinking ability. All of these learning strategies are conducive to the establishment of their lifetime learning ability.

\section{Conclusion}

In May,2007, “College English Curriculum Requirements” issued by Ministry Education (hereinafter referred as requirements) indicates that: college English course is not only a course of basic language knowledge, but also a course for widening knowledge, introducing world culture. Therefore, when designing the college English course, a full consideration of fostering students' cultural qualities and the teaching of international culture should be given, to improve their artistic appreciation to further meet the needs of China's social development and international communication. "Requirements" also points out that college English teaching should be divided into 3 levels, namely normal level, high level and higher level. Colleges and universities should determine the teaching objectives in accordance with the actual situation, and create conditions for students at a relatively high level to achieve a higher level.

Development course of American Society and Culture has met this demand, for America is a major English speaking country, and the relationship between China and America plays an important role in China's foreign relations. By understanding American society and culture, students' English learning interests can be stimulated. Thus, students' English learning ability can be improved, and their knowledge widened, making preparation for their future study and work.

To really achieve this goal, a scientific theory for is crucial to instruct the teaching practice, making changes on the original teaching mode, which was exam-oriented language skills teaching in colleges, realizing the real integration of content and language.

CBI teaching theory abandons the idea of the traditional teaching method, which artificially isolates foreign language teaching. It calls for a foreign language teaching method integrated language and content, which transfers the teaching focus from language learning onto learning a language through knowledge enriching, so as to achieve the targets of integrating of content and language learning, as well as making improvement together. With the instruction of CBI teaching theory, "American Society and Culture" can bring its potential into play, integrating content teaching and language teaching. English is the medium for systematical course teaching, widening students' knowledge; with CBI, students' language ability is improved in culture context and communicative environment.

However, this course is a newly launched one, which is still at the initial stage of a first round pilot teaching, lacking teaching practice foundation and research experience. However, the above problems will be addressed in the research process.

\section{References}

[1] Deputy, B. Content-Based Instruction: Can It Help Ease the Transition from Beginning to Advanced Foreign Language Classes [J], Foreign Language Annals, 2000, (2).

[2] Chang Junyue, Liu Li. The Reference “CBI” Teaching Mode Brings for College Bilingual Teaching [J], Jiangsu Higher Education, 81-83.

[3] Chang Junyue. Empirical Study on CBI Teaching at Basic Stage for English Major[J], Foreign language and foreign language teaching, 2008, (5).

[4] Wei Zhefeng. CBI Teaching Mode and “New Horizon College English”[J], Journal of Anhui University of Technology, 2003, (5). 